\title{
Elicitor-treated extracts of Saururus chinensis inhibit the expression of inducible nitric oxide synthase and cyclooxygenase- 2 enzyme expression in Raw cells for suppression of inflammation
}

\author{
Eun-Ho Lee ${ }^{1} \cdot$ Hye-Jin Park ${ }^{1}$ - Dong-Hee Kim² ${ }^{2}$ Hee-Young Jung ${ }^{3}$. \\ In-Kyu Kang ${ }^{4} \cdot$ Young-Je Cho ${ }^{1}$ (D)
}

Received: 3 April 2019 / Accepted: 17 April 2019 / Published Online: 30 June 2019

(C) The Korean Society for Applied Biological Chemistry 2019

\begin{abstract}
Elicitor treatment was performed to increase the antiinflammatory activity of useful biological sources. The result showed that elicitor-treated Saururus chinensis leaf extracts positively affected nitric oxide (NO) production, and the expression of inducible NO synthase and cyclooxygenase- 2 compared to extracts not exposed to elicitor treatment. This finding identified elicitor treatment as a suitable strategy for increasing the biological activity of $S$. chinensis. Therefore, elicitor-treated $S$. chinensis is useful both as health functional and medicinal materials.
\end{abstract}

Keywords Cyclooxygenase- 2 - Elicitor · Inducible nitric oxide synthase $\cdot$ Nitric oxide $\cdot$ Saururus chinensis extracts

\section{Introduction}

The secondary metabolites produced by medicinal herbs including

Young-Je Cho $(\bowtie)$

E-mail: yjcho@knu.ac.kr

${ }^{1}$ School of Food Science and Biotechnology/Food and Bio-Industry Research Institute, Kyungpook National University, 80 Daehakro, Bukgu, Daegu 41566, Republic of Korea

${ }^{2}$ National Development Institute of Korean Medicine, Gyeongsan 38540 , Republic of Korea

${ }^{3}$ School of Applied Biosciences, Kyungpook National University, 80 Daehakro, Bukgu, Daegu 41566, Republic of Korea

${ }^{4}$ Department of Horticultural Science, Kyungpook National University, 80 Daehakro, Bukgu, Daegu 41566, Republic of Korea

This is an Open Access article distributed under the terms of the Creative Commons Attribution Non-Commercial License (http://creativecommons. org/licenses/by-nc/3.0/) which permits unrestricted non-commercial use, distribution, and reproduction in any medium, provided the original work is properly cited.
Saururus chinensis [1-7] have various specific pharmacological activity, which has increased the interest in these substances. There are 4,000 native plants currently known and only approximately 400 species inhabit S. Korea. These native plants, which have high monetary value, were exported to foreign nations from S. Korea and are currently being reimported [8]. Improved strains of flowering plants such as Ms. Kim lilac (Syringa velutina var. kamibayashii T.) and daylily (Hemerocallis fulva L.) are being sold widely. Saururus chinensis leaves contain high amounts of phenolic compounds such as mannasantin A, mannasantin B, sauceneol D and avicularin, etc., which have anti-inflammation activity $[9,10]$. The components contained in Saururus chinensis have been shown to have protective activity in interstitial cell, exert antibacterial and antioxidant effects, and strengthen capillary vessels [4-7].

In addition, ginkgo leaf from S. Korea was developed into a blood circulation enhancer and has been reimported at a high value. The value of native plants has increased recently [11,12] and, therefore, research into developing techniques for producing useful materials with high value from a cash crop naturally growing in our country has increased. These research studies tend to identify globally competitive, originative techniques and high value producing systematic applications using grafting effects, ingredient analysis, cultural environment analysis and biotechnology based on experiences with folk remedies and clinical trials $[13,14]$.

Macrophages, one of the cell types involved in the inflammatory response, have a significant effect on immune and inflammatory reactions. NO, a reactive radical molecule in cells, is generated from L-arginine through its oxidation by inducible NOS (iNOS), the latter being well known in the defense response against various inflammatory diseases, circulatory disorders, and cancers [15]. Prostaglandin $\mathrm{E}_{2}\left(\mathrm{PGE}_{2}\right)$, also known as dinoprostone, is a principal inflammatory mediator that is generated from arachidonic 
acid, which is converted by cyclooxygenase (COX)-2 [16].

Elicitation technique involves artificially inducing phytoalexin, which is produced by plants as a protective mechanism against attacks by potentially deleterious substances such as pathogens. By treating the plant with an inducing agent shortly before harvesting, a high-quality oriental material or herb with a high content of useful contents is obtainable. Therefore, elicitation is an economical and efficient biomass treatment method.

In this study, we established an elicitation technique, which was applied to garden cultured Saururus chinensis, with the aim of improving and enhancing the production of pharmacologically active contents by medicinal herbs. In addition, the main achievement was the development of techniques to maximize the pharmacologically active contents to ensure the pharmacological competitiveness rather than price competitiveness.

\section{Materials and Method}

Production and application of elicitor on Saururus chinensis The elicitor was produced by treating yeast extract with protease and adding ethanol to generate a precipitate, which was collected and dried to produce the yeast extract powder. One kilogram of yeast extract powder was homogenized with $5 \mathrm{~g}$ copper chloride $\left(\mathrm{CuCl}_{2}\right)$ to produce the elicitor powder according to the method of Cho et al. [9].

The elicitor was applied three times at 1.5 and $3 \mathrm{mg} / \mathrm{L}$ (groups $\mathrm{A}$ and $\mathrm{B}$, respectively) per application. The first application was carried out when the $S$. chinensis leaves had grown to approximately one-fourth their full size (April 30th). The elicitor was sprayed directly on the bottom part of the leaves on a $4 \mathrm{~m}^{2}$ area in both groups A and B. A similar second application was carried out at 50\% leaf growth (May 7th). The final application was carried out at $75 \%$ leaf growth (May 14th). In total, groups A and B were treated with elicitor concentrations of 4.5 and $9.0 \mathrm{mg}$, respectively, on each $4 \mathrm{~m}^{2}$ area until the harvest.

\section{Extraction process of elicitor-treated $\boldsymbol{S}$. chinensis}

To prepare the water extract, $200 \mathrm{~mL}$ distilled water was added to $1 \mathrm{~g}$ of the dry plant sample, boiled until the solution volume was reduced to $100 \mathrm{~mL}$, and then cooled. For the ethanol extract, 100 $\mathrm{mL} 60 \%$ ethanol was added to the plant sample with stirring for $24 \mathrm{~h}$, followed by homogenization for $1 \mathrm{~min}$ using a homogenizer at 20,000 rpm. The extract was filtered with Whatman No. 1 filter paper and concentrated using a rotary vacuum evaporator (Eyela NE, Tokyo, Japan) if needed and used as the sample.

\section{Phenol compound determination}

Briefly, $240 \mu \mathrm{L} 5 \%$ sodium carbonate $\left(\mathrm{Na}_{2} \mathrm{CO}_{3}\right)$ solution was added to $2 \mathrm{~mL}$ of the extract, followed by $120 \mu \mathrm{L} 1 \mathrm{~N}$ Folinciocalteu reagent as the color-developing reagent and the mixture was thoroughly mixed. The color was expressed by leaving it for 10 min then the optical density (OD) was determined within $1 \mathrm{~h}$ at $725 \mathrm{~nm}$ and then used to construct a standard curve using gallic acid [17].

\section{Cell toxicity analysis using 3-(4,5-dimethylthiazol-2-yl)-2,5- diphenyltetrazolium bromide (MTT) assay}

The Raw 264.7 murine macrophage cell line was purchased from Korean Cell Line Research Foundation and cultured for $72 \mathrm{~h}$ at 37 ${ }^{\circ} \mathrm{C}$ in an atmosphere of $5 \% \mathrm{CO}_{2}$ with mixed medium of $10 \%$ fetal bovine serum (FBS, Gibco Co. Waltham, MA, USA), $100 \mathrm{U} / \mathrm{mL}$ penicillin and $100 \mu \mathrm{g} / \mathrm{mL}$ streptomycin in Dulbecco's modified Eagle's medium (DMEM). The cell condition was maintained in an atmosphere of $5 \% \mathrm{CO}_{2}$ and subcultured at a density of 2-3× $10^{6} \mathrm{CFU} / \mathrm{mL}$ in a cell culture dish. For the experiments, the passages condition of $80 \%$ confluency and 20 times. The cells were cultured for $12 \mathrm{~h}$ with the FBS-free medium before the experiment $[18,19]$.

\section{Nitric oxide (NO) determination}

NO levels were determined by measuring NO amount in the cell supernatant as nitrite and nitrate. Griess reagent (Sigma-Aldrich, St. Louis, MO, USA) was used to stabilize nitrite reduced to nitrate. At $80 \%$ confluence, $2 \times 10^{6}$ cells were washed two times with phosphate-buffered saline (PBS) and cultured with serumfree culture medium in a six-well plate. Then, the cells were stimulated by adding $50 \mu \mathrm{M}$ lipopolysaccharide (LPS) to all wells except the control group. The sample was added at a concentration range of $60-80 \mu \mathrm{g} / \mathrm{mL}$ and incubated for $2 \mathrm{~h}$. The NO production amount was determined by measuring the OD of the collected supernatant at $540 \mathrm{~nm}$ after a $10 \mathrm{~min}$ reaction in the dark [19,20]. The inhibitory activity (\%) was calculated as follows: (1absorbance of sample/absorbance of control) $\times 100$.

\section{Analysis of inducible nitric oxide synthase (iNOS) expression using western blotting}

Raw cells were allowed to reach $80 \%$ confluence, the DMEM was then discarded and replaced with serum-free Eagle's minimum essential medium, and then the cells were cultured with the test substances under the same conditions used above. At the predetermined time, the cells were washed two times, the supernatant was discarded, and then the cells were collected using a scrapper and then homogenized in lysis buffer. The protein concentration of the cultured cells was determined by measuring the OD value based on the standard curve constructed using bovine serum albumin. The normalized protein sample was used as the western blotting sample after dyeing with Coomassie blue. The sample was separated using $10 \%$ sodium dodecyl sulfate (SDS)-polyacrylamide gel electrophoresis, the gel was immersed for 10-15 min in transfer buffer, placed between two sponge sheets in transfer buffer, and then one sheet of filter paper was placed on top. Then, $3 \mathrm{~mm}$ filter paper and a nitrocellulose filter were also immersed in the buffer. The nitrocellulose paper and gel were osculated between the 

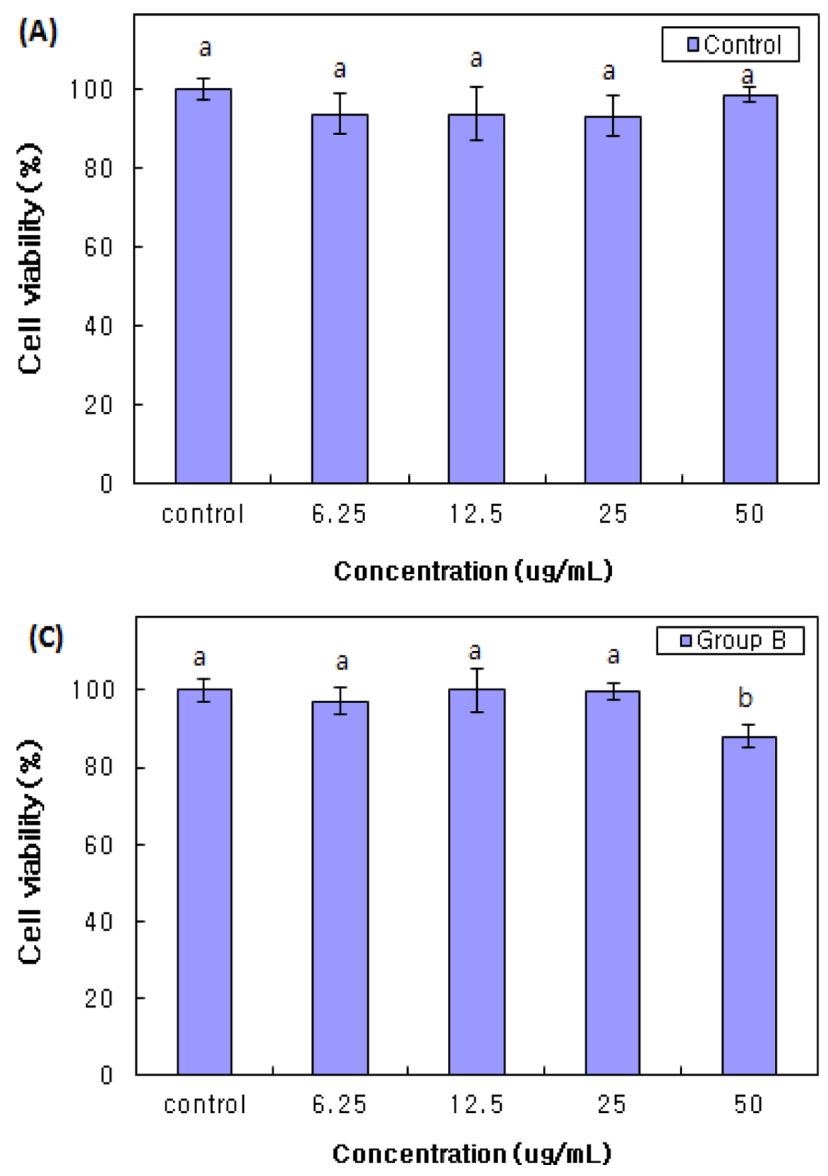

sponges then the proteins were transferred by plugging the electrodes. After transferring for over $1 \mathrm{~h}$ at $190 \mathrm{~mA}$, the transfer blot was immersed in Ponceau S for $2 \mathrm{~min}$, and the bands were detected. The background was removed by incubation in blocking buffer after washing two times with PBS. Then the blot was incubated with the primary antibody $(1: 1,000)$, followed by the secondary antibody $(1: 1,000)$. The blot was washed with PBS plus $0.5 \%$ Tween 20 several times, and then the bands were visualized on a film using an enhanced chemiluminescence (ECL) kit (Amersham Pharmacia, England) [19,21].

\section{Analysis of cyclooxygenase (COX)-2 expression using western blotting}

To determine the activity of COX-2 protein, Raw 264.7 macrophage cells were stabilized by culturing for $24 \mathrm{~h}$ in $100 \pi$ tissue culture dish at a density of $2 \times 10^{4}$ cells $/ \mathrm{mL}$ and each well was treated. After removing the medium, different concentrations (6.25-25 $\mu \mathrm{g} /$ $\mathrm{mL}$ ) of treated medium were used to cultivate the cells for $24 \mathrm{~h}$. Then, the medium was removed, and the cells were washed twice with PBS. The cells were lysed with $100 \mu \mathrm{L}$ lysis buffer (complete mini 1 added to the radioimmunoprecipitation assay buffer 10 $\mathrm{mL}$ ) and centrifuged for $20 \mathrm{~min}$ at $12,000 \mathrm{rpm}$ at $4{ }^{\circ} \mathrm{C}$. The supernatant was collected and placed in a new tube, which was stored at $-20{ }^{\circ} \mathrm{C}$ for further use or protein determination. The

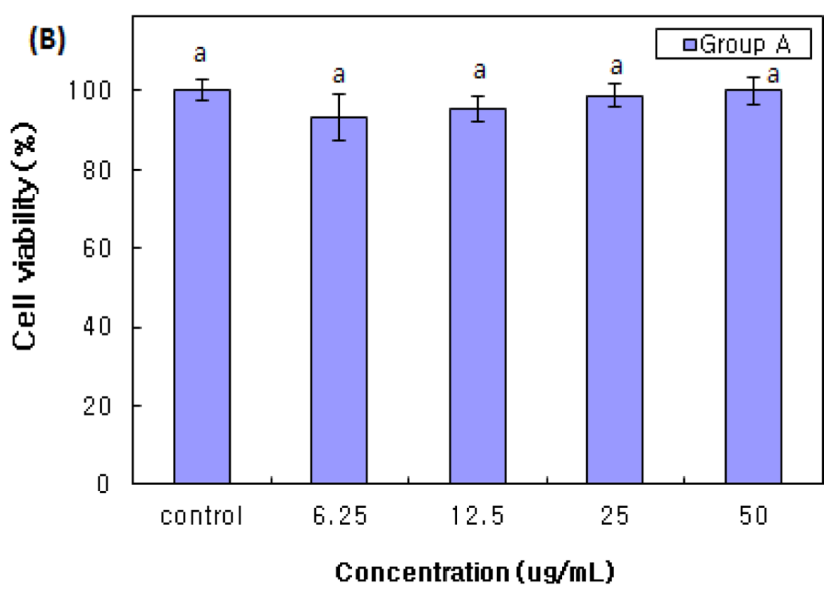

Fig. 1 Cell viability following incubation with extracts of Saururus chinensis with elicitor and without elicitor treatment. A: control (no elicitor treatment), B: group A (1.5 mg elicitor/leaf $\mathrm{g}$ treatment), C: group $\mathrm{B}(3.0 \mathrm{mg}$ elicitor/leaf $\mathrm{g}$ treatment)

supernatant collected after centrifugation was determined using the Bradford assay. Then, $20 \mu \mathrm{L}$ of protein samples were separated using 10\% SDS-PAGE. The separated proteins were transferred onto a polyvinylidene fluoride membrane using semidry transfer cell equipment (Bio-Rad, Hercules, CA, USA) and incubated for 1 hour with blocking buffer (5\% skim milk in Tris-buffered saline plus Tween [TBST]) at room temperature. The membrane was washed with TBST three times every $10 \mathrm{~min}$ and incubated overnight with diluted primary antibodies against, iNOS (BD Bioscience, Santa Cruz, CA, USA. 1:1000), COX-2 (Cayman, Ann Arbor, MI, USA. 1:1000), and glyceraldehyde 3-phosphate dehydrogenase (GAPDH, BD Bioscience, Santa Cruz, CA, USA. 1:1000), at $4{ }^{\circ} \mathrm{C}$. Then, the membrane was washed with TBST again three times for $10 \mathrm{~min}$ each and then incubated for $2 \mathrm{~h}$ at room temperature with secondary mouse anti-rabbit IgG horseradish peroxidase (HRP) and bovine anti-goat IgG HRP (Santa Cruz, 1:1000). After washing three times, the membrane was reacted with ECL (Millipore) solution in a darkroom and exposed to X-ray film. The bands were visualized using a molecular imager (Bio-Rad) [19,21].

\section{Statistical analysis}

The experiments were repeated three times, and the results were calculated as averages with standard deviations. The statistical 

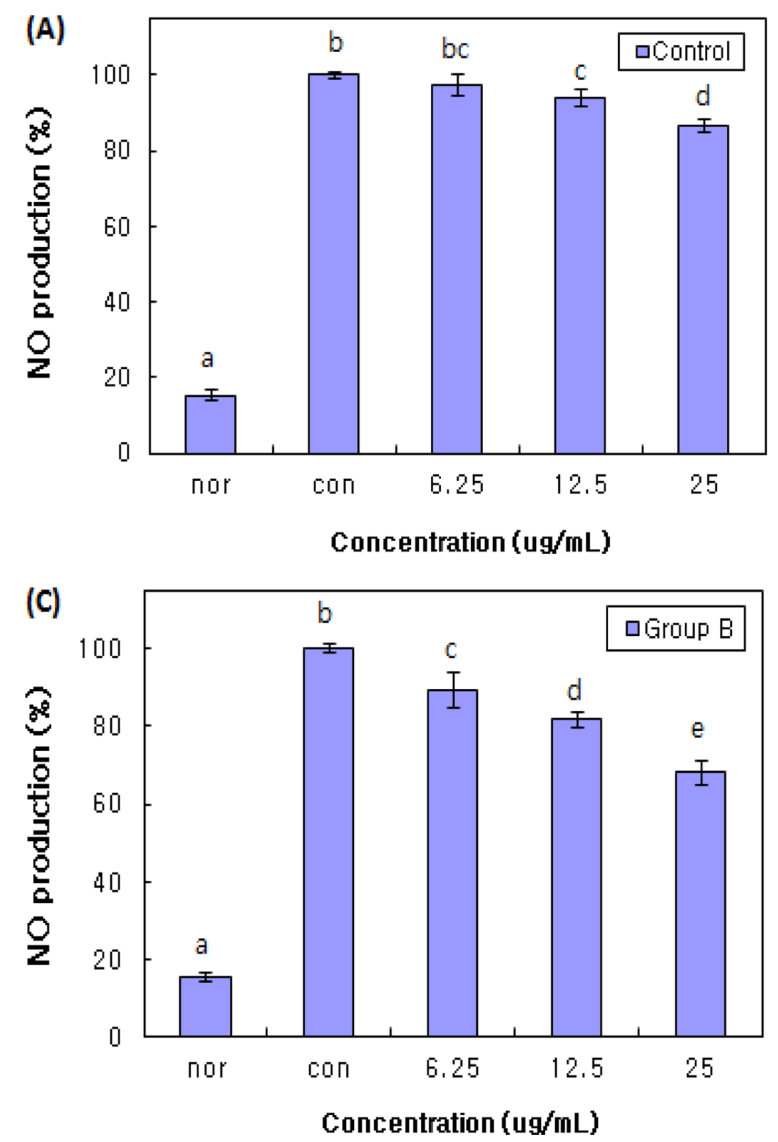

analysis was performed using the statistical package for the social sciences (SPSS) 23 for Windows (SPSS, Chicago, IL, USA) program and Duncan's multiple range test (one-way analysis of variance [ANOVA] at 95\% significance level.

\section{Results and Discussion}

\section{MTT assay of elicitor-treated $\boldsymbol{S}$. chinensis extracts}

The MTT assay was performed to determine the cell survival rate and cytotoxicity of the extracts. Treatment of the cells with the elicitor-treated $S$. chinensis extracts at $6.25-50 \mu \mathrm{M} / \mathrm{mL}$ concentration had no effects on the cell viability (Fig. 2).

\section{Inhibition of NO expression by elicitor-treated $S$. chinensis extracts}

The endotoxin LPS is a component of gram-negative cell outer membranes. Macrophages are activated by small amounts of LPS, which leads to the production and release of cytokines, NO, and other factors that induce the various physiological responses mediated by LPS [22]. NO generation normally has an important role in killing and removing bacteria and tumors, but excessive levels induced by pathological processes can cause inflammation, organ damage, genetic mutations, and neural damage [23,24].

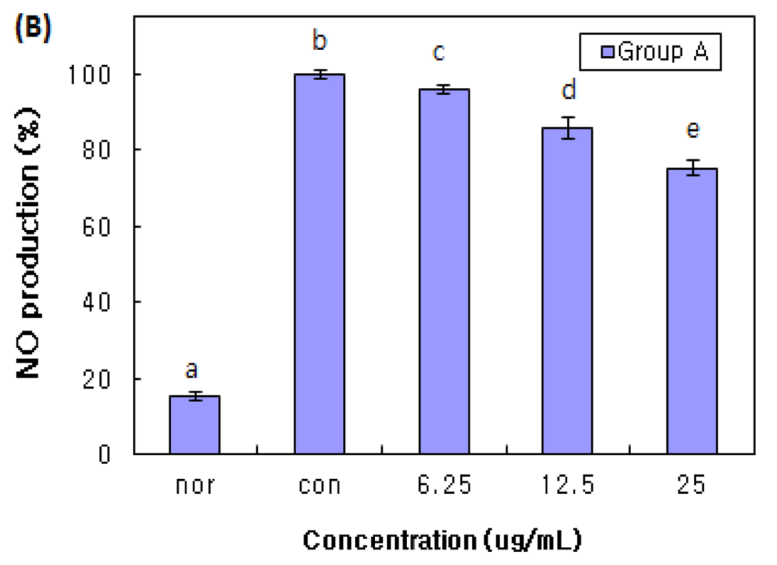

Fig. 2 Inhibition of nitric oxide (NO) production by elicitor-treated Saururus chinensis extracts. A: control (no elicitor treatment), B: group A (1.5 mg elicitor/leaf $\mathrm{g}$ treatment), C: group B (3.0 mg elicitor/leaf $\mathrm{g}$ treatment)

To determine if the $S$. chinensis extract inhibits NO production by Raw 264.7 cells, they were incubated with different extract concentrations and Fig. 3 shows that the LPS-stimulated group exhibited $200 \%$ increase of NO expression, which was two times more than that of the unstimulated group. Elicitor-treated S. chinensis extracts inhibited NO expression concentration-dependently. Elicitortreated $S$. chinensis extract at $100 \mu \mathrm{g} / \mathrm{mL}$ inhibited NO production by $>80 \%$, which was higher than the $70 \%$ inhibition induced by the $S$. chinensis extract without elicitor treatment. In addition, group B showed higher inhibition of NO production than group A, which exhibited similar levels to those of the normal group. The extract was expected to amplify the anti-inflammation effect and immune function of Raw 264.7 macrophage cells induced by LPS. In addition, amplification of the expression of determined transcription factors that interact with NO was expected.

\section{Inhibition of iNOS expression by elicitor-treated $S$. chinensis extracts}

$\mathrm{NO}$ is a free radical generated throughout the body that controls biological functions such as angiectasis, smooth muscle contraction, neuronal signal transduction, platelet aggregation inhibition, and immunomodulation. It also has anticancer and antibacterial properties. However, excessive NO production can cause various inflammatory diseases, septic symptoms by excessive angiectasis, wound healing 
(A)

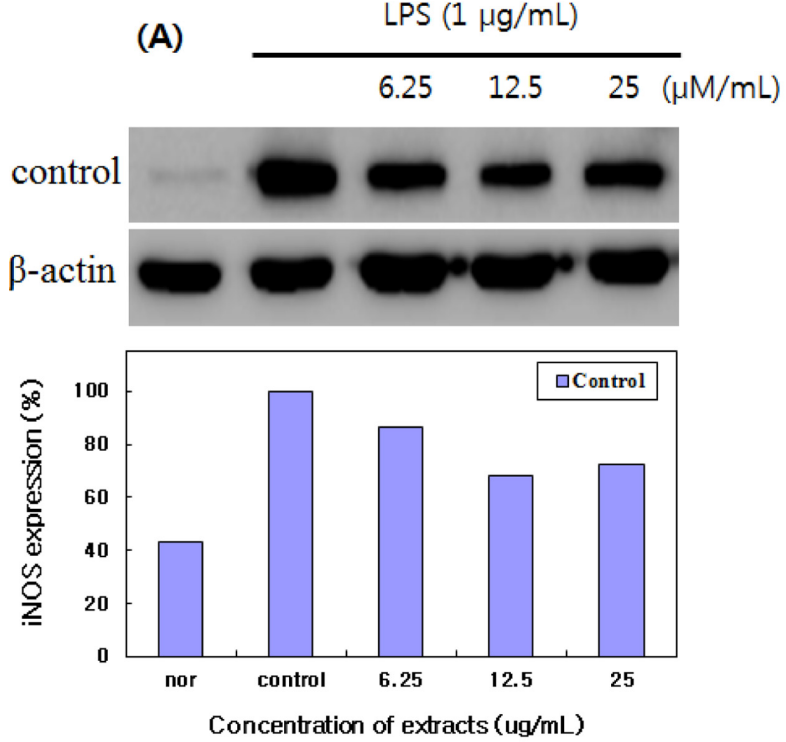

(C)

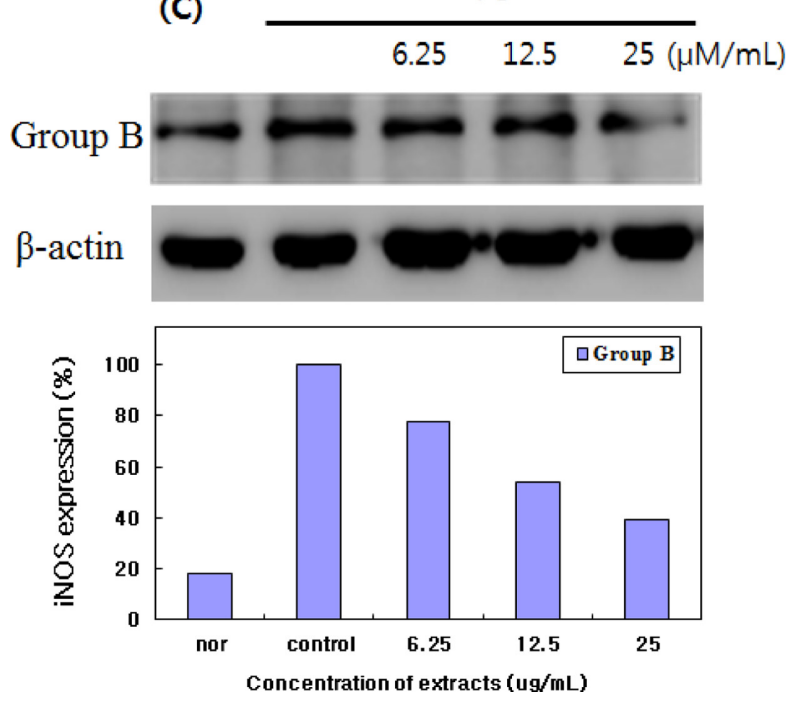

inhibition, immune system dysfunction, and cell withering.

Inflammatory factors $\mathrm{NO}, \mathrm{PGE}_{2}$, and other substances are formed during the inflammatory process by iNOS and COX-2. NO have various biological functions such as body defense, signal transmission, neurotoxicity, and angiectasis. NO is synthesized by NOS, which consists of the following three types that convert Larginine to L-citrulline: type I (neuronal NOS, nNOS); II (iNOS); and which convert NOS can also be classified into three different types: I, inducible NOS; II (only expressed following exposure to specific stimulating inflammatory factors such as lipopolysaccharide (LPS), cytokines, and bacterial toxins; and III (endothelial NOS), which produces NO for maintaining homeostasis [25]. The different iNOS isoforms are widely expressed and have important pathological functions. Especially, iNOS, which is induced by stimulation, produces quantities of $\mathrm{NO}$ for a long time. The produced NO
(B) \begin{tabular}{lll}
$\operatorname{LPS}(1 \mu \mathrm{g} / \mathrm{mL})$ \\
\hline $6.25 \quad 12.5 \quad 25(\mu \mathrm{M} / \mathrm{mL})$
\end{tabular}
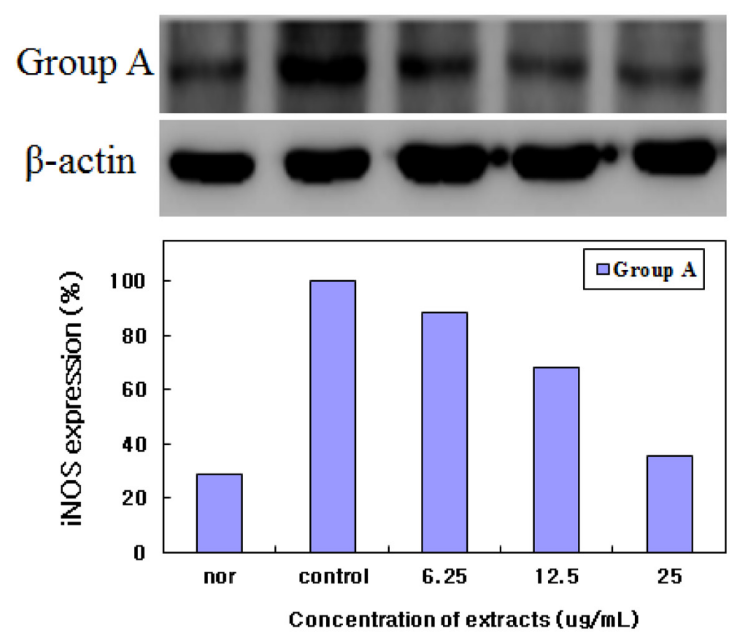

Fig. 3 Inhibitory effects of elicitor-treated Saururus chinensis extracts on inducible nitric oxide synthase (iNOS) expression. A: control (no elicitor treatment), B: group A (1.5 mg elicitor/leaf g treatment), C: group B (3.0 $\mathrm{mg}$ elicitor/leaf $\mathrm{g}$ treatment)

characteristically activates guanylyl cyclase, causing toxicity to nearby organs. An anti-inflammatory effect was expected to be identified by iNOS protein level decrease in RAW 264.7 cells stimulated with LPS and by determining the COX-2 protein level, which is a factor that increases proinflammatory cytokines such as tumor necrosis factor (TNF)- $\alpha$ and interleukin (IL)-6 in monocytes and macrophages [26].

To investigate the relationship between iNOS protein and NO production inhibition mechanisms, iNOS protein expression was determined in the cytoplasm using western blot analysis. As shown in Fig. 4A-C, elicitor-treated $S$. chinensis extract inhibited iNOS expression concentration-dependently. At $25 \mu \mathrm{M} / \mathrm{mL}$, elicitortreated S. chinensis extracts showed $70 \%$ inhibition of iNOS expression, which was $40 \%$ higher than that of the $S$. chinensis extracts not elicitor-treated. Group B showed higher iNOS expression 
(A)
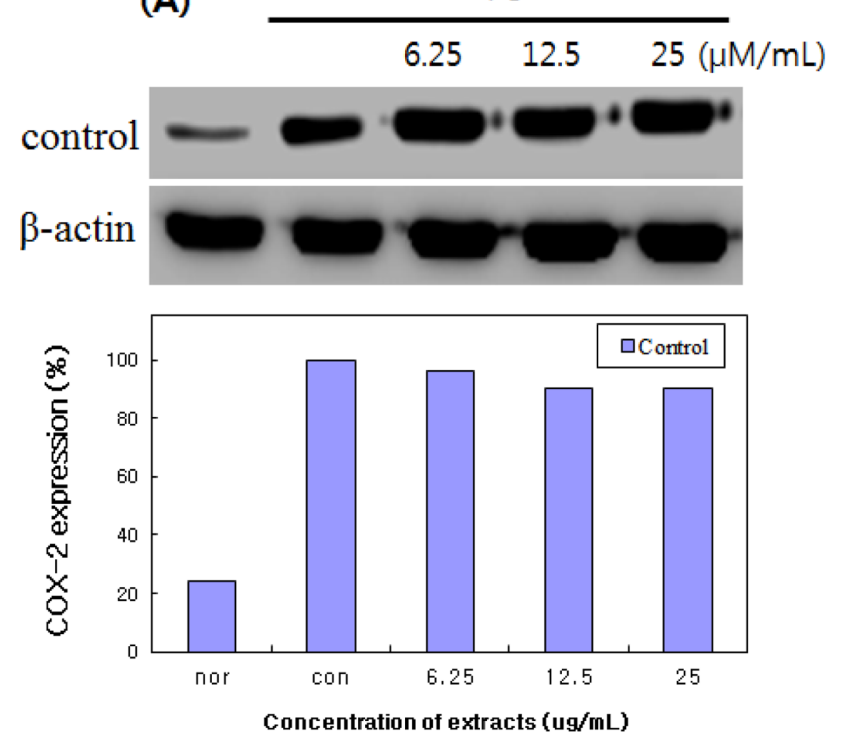

(C)
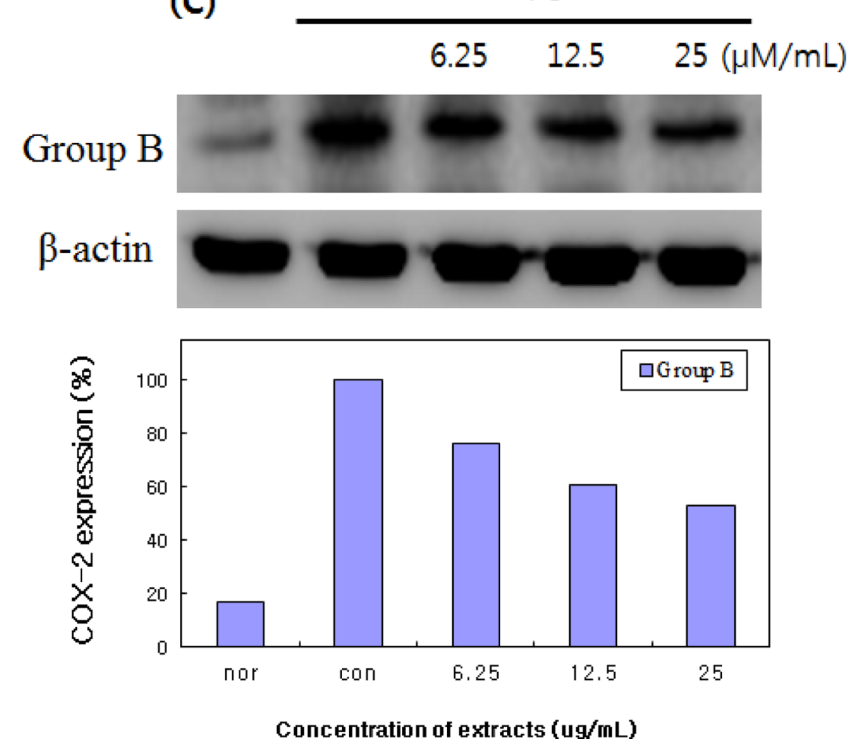

inhibition than group A, which showed similar inhibition to that of the normal group. Similar to previous experimental results, a trend of amplified total phenolic compounds and content of useful substances such as vicularin, manassantin A, manassantin B, and saucerneol D was observed. The analysis of the western blot results showed that the elicitor-treated $S$. chinensis extract inhibited the iNOS protein expression more than the untreated extract did, which indicates it reduced LPS-induced inflammation by inhibiting iNOS expression.

\section{Inhibition of COX-2 expression by elicitor-treated $S$. chinensis extracts}

COX-2 is produced by the activation of mitogen-activated protein kinase kinase- 1 and nuclear factor- $\mathrm{kB}$ by prooxidant or proin-
(B)
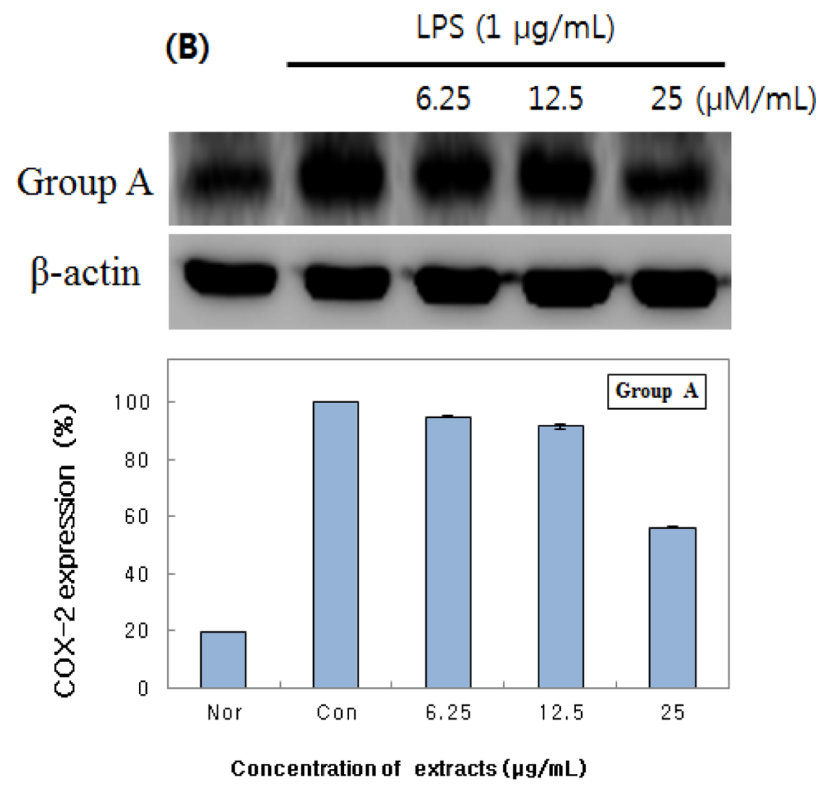

Fig. 4 Inhibitory activity of elicitor-treated Saururus chinensis extracts on cyclooxygenase (COX)-2 expression. A: control (no elicitor treatment), B: group A (1.5 mg elicitor/leaf g treatment), C: group B (3.0 mg elicitor/ leaf $g$ treatment)

flammatory stimuli (e.g., TPA, LPS, TNF $\alpha$, and ROI), and it has an important role in the inflammatory reaction by increasing prostaglandin synthesis [27]. In addition, COX-2 expression in monocytes is increased by proinflammatory agents such as IL-1 $\beta$, TNF- $\alpha$, phosphatidic acid, and fibroblast growth factor and inhibited by glucocorticoids, IL-4, and IL-13 [28,29]. Therefore, selective inhibitor development for COX-2 is a potential targeted molecular strategy for inflammation treatment. The induction of the inflammatory factor, COX-2 protein, by LPS was inhibited by elicitor-treated $S$. chinensis extracts concentration-dependently (Fig. 5A-C). Elicitor-treated $S$. chinensis extract at $25 \mu \mathrm{M} / \mathrm{mL}$ showed approximately $80 \%$ inhibition of COX-2 expression, which was much higher than the $20 \%$ induced by the untreated extracts. In addition, treated of group $B$ at $6.25-12.5 \mu \mathrm{M} / \mathrm{mL}$ 
inhibited the iNOS expression effect more than that of group A, showing similar inhibition to that of the normal group.

Similar to previous experimental results, we observed that the extracts tended to inhibit the amplified NO production. Analysis of the western blotting results showed that the elicitor-treated $S$. chinensis extracts showed higher inhibition of the LPS-induced iNOS and COX-2 protein expression than the untreated extracts did, which indicates that the inflammatory reaction was reduced by the inhibition of iNOS and COX-2 protein expression.

It has been reported by Park et al. [10] that the gastritis inhibitory compounds in $S$. chinensis are avicularin, manassantin A, manassantin B, and saucerneol D. In the present study, the NO, iNOS and COX-2 levels as anti-inflammatory activities were increased in elicitor-treated groups A and B, compared to nontreated control group. These results indicate that elicitor treatment amplifies these biological compounds on inflammation during the growth of $S$. chinensis.

\section{References}

1. Kwon SA (1999a) A second series about Saururus chinensis and Houttuynia cordata Thunberg. J Kor Oriental Drug 2: 18-20

2. Kwon SA (1999b) A second series about Saururus chinensis and Houttuynia cordata Thunberg. J Kor Oriental Drug 3: 28-31

3. Park JH, Lee CK (2000) In The encyclopedia of medicinal plants. Shinilbook Publishing Co., Korea

4. Kwon SH (1996) The isolation of anti-hepatotoxic constituents from Saururus chinensis. MS Thesis, Seoul national university, Korea

5. Lee ST, Lee YH, Choi YJ, Lee YH, Choi JS, Heo JS (2001) Yield and bioactive component on different compostamounts and culture method of Saururus chinensis Bail. Kor J Med Crop Sci 9: 220-224

6. Lee ST, Park JM, Lee HK, Kim MB, Cho JS, Heo JS (2000) Component comparison in different growth stages and organs of Saururus chinensis Bail. Kor J Med Crop Sci 8: 312-318

7. Kim BH, Song WS (2000) The dyeability and antimicrobial activity of Saururus chinensis (I). J Kor I lomc Economics 38: 1-9

8. Jhoo JW (2008) Anti-inflammatory effects of purpurogallin carboxylic acid, an oxidation product of gallic acid in fermented tea. Kor J Food Sci technol 40: 707-711

9. Cho YJ, Park SY, Kim KB (2014) Cultivation method of increased inhibitory compounds in Saurrus chinensis by yeast to enzyme degradation. Patent 10-1469901, Korea

10. Park SY, Song IH, Cho YJ (2018) Elicitor treatment potentiates the preventive effect of Saururus chinensis leaves on stress-induced gastritis. Appl Biol Chem 61: 423-431

11. Cho YJ, Ju IS, Chun SS, An BJ, Kim JH, Kim MU, Kwon OJ (2008) Screening of biological activities of extracts from Rhododendron mucronulatum turcz. flowers. J Kor Soc Food Sci Nutr 37: 276-281

12. Joo EY, Lee YS, Kim NW (2007) Polyphenol compound contents and physiological activities in various extracts of the Vitex rotundifolia stems.
J Kor Soc Food Sci Nutr 36: 813-818

13. Makins R, Ballinger A (2004) Gastrointestinal side effect of drugs. Expert Opin Drug Saf 2: 421-429

14. Jeong HJ, Lee KY, Hong SY, HEO NK, Kim HY (2013) Antiinflammatory effects of Xanthoceras sorbifolia seeds oil on Raw 264.7 macrophages and TPA-induced ear edema mice. J Forest Sci 29: 324 330

15. Willeaume V, Kruys V, Mijatovic T, Huez G (1995) Tumer necrosis factor-alpha production induced by viruses and by lipopolysaccharides in macrophages: similarities and differences. J Inflamm 46: 1-12

16. Walsh NC, Crotti TN, Goldring SR, Gravallese EM (2005) Rheumatic diseases: the effects of inflammation on bone. Immunol Rev 208: 228 251

17. Duval B, Shetty K (2001) The stimulation of phenolics and antioxidant activity in pea (Pisum sativum) elicited by genetically transformed Anise root extract. J Food Biochem 25: 361-377

18. Carmichael J, DeGraff WG, Gazdar AF, Minna JD, Mitchell JB (1987) Evaluation of a tetrazolium based semiautomated colorimetric assay: assessment of chemosensitivity testing. Cancer Res 47: 936-942

19. Cho YJ, An BJ (2008) Anti-inflammatory effect of extracts from Cheongmoknosang (Morus alba L.) in lopopolysaccharide-stimulated Raw cells. J Kor Soc Appl Biol Chem 51: 44-48

20. Ryu JH, Ahn H, Kim JY, Kim YK (2003) Inhibitory activity of plant extracts on nitric oxide synthesis in LPS-activated macrophage. Phyto Res 17: 485-489

21. Cho YJ (2011) Anti-inflammatory effect of Jatrorrhizine from Phellodendron amurense in Lipopolysaccharide-stimulated Raw 264.7 cells. J Appl Biol Chem 54: 114-119

22. Syu-ichi K, Ai S, Ayako T, Takako H, Yu O, Mayuko U, Yutaro O, Norimichi N, Masaaki I (2005) Inhibitory effect of naringin on lipopolysaccharide (LPS)- induced endotoxin shock in mice and nitric oxide production in Raw 264.7 macrophages. Life Sci 25: 1-9

23. Kim MK, Kim DY (2015) Anti-inflammatory effect of barley leaf ethanol extract in LPS-stimulated RAW264.7 macrophage. Kor J Food Preserv 22: 735-743

24. Kim DH, Cho JH, Cho YJ (2016) Anti-inflammatory activity of extracts from ultra-fine ground Saururus chinensis leaves in lipopolysaccharidestimulated Raw 264.7 cells. J Appl Biol Chem 59: 37-43

25. Kim NK, Kim MH, Yoon CS, Choi SW (2006) Studies on the antiinflammatory activity of Paulownia coreana Uyeki leaf extracts. J Soc Cosmet Sci Kor 32: 241-247

26. Lee SJ, Lee DG, Kim MY, Kong SC, Yu KH, Kim YY, Lee SH (2016) Enhancement of anti-inflammatory activity by fermentation of Sargassum siliquanstrum. J Life Sci 26: 318-324

27. Park SJ, Shin JS, Cho W, Cho YW, Ahn EM, Baek NI (2008) Inhibition of LPS induced iNOS, COX-2 and cytokines expression by kaempferol3-O- $\beta$-D-sophoroside through the NF-âB inactivation in RAW 264.7 cells. Kor J Pharmacogn 39: 95-103

28. Park SJ, Kim JY, Jang YP, Cho YW, Ahn EM, Baek NI (2007) Inhibition of LPS induced iNOS, COX-2 and cytokines expression by genistein-4'O-á-L-rhamno pyranosyl-(1-2)-â-D-glucopyrano side through the NF-êB inactivation in Raw 264.7 Cells. Kor J Pharmacogn 38: 339-348

29. Jung YS, Eun CS, Jung YT, Kim HJ, Yu MH (2013) Anti-inflammatory effects of Picrasma quassioides BENN leaves extracts. J Life Sci 23: $629-636$ 